\title{
ARTICULANDO RACA E CLASSE: EFEITOS PARA A CONSTRUÇÃO DA IDENTIDADE AFRODESCENDENTE
}

\author{
José LicínIo BACKes*
}

\begin{abstract}
RESUMO: $\mathrm{O}$ artigo sustenta que raça e classe estão articuladas no contexto brasileiro, produzindo efeitos na identidade afrodescendente. Especificamente, neste texto estão em jogo os efeitos que o acesso à universidade tem para os afrodescendentes na construção de sua identidade cultural. Considera os universitários beneficiados pelo projeto Negraeva, iniciado em 2002, projeto de apoio para a manutenção de afrodescendentes nas universidades, desenvolvido pela Comunidade Negraeva, localizada em Campo Grande (MS). Para compreender os efeitos que o acesso à universidade tem na construção de sua identidade cultural, recorreu-se a entrevistas semi-estruturadas com estes sujeitos. Perceberam-se vários efeitos, destacandose que os afrodescendentes passam a ter mais força para reivindicar direitos, questionar atitudes discriminatórias, desconstruir o mito da democracia racial, construindo uma identidade cultural/racial/étnica de forma a se verem e serem vistos pelos outros como uma identidade legítima, que não pode ser usada para justificar a dominação e a exploração econômica como se fez e se faz no Brasil desde os tempos da colonização.
\end{abstract}

Palavras-chave: Identidade. Diferença. Afrodescendente. Cultura.

ARTiCUlating RACE AND ClASS:

EFFECTS ON THE CONSTRUCTION OF THE AFRO-DESCENDANT IDENTITY

ABSTRACT: This paper asserts that race and class are articulated in the Brazilian context and produce effects on the afro-descendant identity. It specifically focuses on the effects of the access to university on the construction of the afro-descendant cultural identity. To

* Doutor em educação e professor do Programa de Mestrado em Educação da Universidade Católica Dom Bosco (UCDB).E-mail: backes@ucdb.br 
Articulando raça e classe: efeitos para a construção da identidade afrodescendente

understand such effects, semi-structured interviews were conducted with university students benefited by the Negraeva project, developed, from 2002 on, by the Negraeva Community, Campo Grande (MS), to maintain afro-descendants in universities. Different effects were perceived, especially that the afro-descendants gain more strength to vindicate their rights, question discriminating attitudes and do away with the myth of a racial democracy. They thus construct a cultural/racial/ethnic identity that allows them to see themselves and be seen by the others as a legitimate identity, which cannot be used to justify the domination and economic exploitation which has taken place in Brazil since the times of colonization.

Key words: Identity. Difference. Afro-descendant. Culture.

artigo inspira-se no campo teórico dos Estudos Culturais. Este campo afirma que não há razões para apostas em noções homogêneas de identidades coletivas, seja de raça/etnia, classe, cultura ou gênero, pois os sujeitos são imprevisíveis e nômades. Segundo Donald (2000), uma parte da história do sujeito encontra-se nas "(...) improvisações da vida cotidiana que, embora sejam pouco reconhecidas, são bastante engenhosas" (p. 65). É na vida cotidiana que os sujeitos se vêem diante do dilema da reprodução cultural e da transgressão cultural, articulando a sua identidade no encontro com as diferenças. Assim, quando a vida cotidiana adquire novos contornos, mudam também os processos de construção da identidade cultural. Mudando as identidades, muda também a cultura, pois os sujeitos mudam a cultura e a cultura muda os sujeitos. Desta forma, quando determinados grupos culturais que historicamente foram excluídos de alguns espaços, como no caso desta pesquisa, do espaço da universidade, o ocupam, novos sentidos são produzidos, provocando efeitos nas identidades culturais, fomentando negociações: "Com a palavra negociação, tento chamar a atenção para a estrutura de interação que embasa os movimentos políticos que tentam articular elementos antagônicos e oposicionais sem a racionalidade redentora da superação dialética ou da transcendência" (Bhabha, 2001, p. 52).

Neste sentido, pode-se dizer que as negociações fazem parte da cultura. Cultura é o campo onde o sentido das coisas, das identidades, das diferenças é negociado e construído: “(...) toda a nossa conduta e todas as nossas ações são moldadas, influenciadas e, desta for- 
ma, reguladas normativamente pelos significados culturais" (Hall, 1997, p. 41). Ela é um campo de luta e contestação. O sentido é produzido no interior da cultura e está circunscrito ao próprio contexto cultural. Não existe sentido fora da cultura. Estes sentidos/significados são produzidos socialmente, o que significa reconhecer que são estabelecidos pelas relações de poder. A cultura produz as identidades e as diferenças. A cultura produz identidades normais/anormais, legítimas/ ilegítimas, dignas/indignas, brancas/negras... Como afirma Silva (1996), as narrativas culturais “(...) representam os diferentes grupos sociais de forma diferente: enquanto as formas de vida de alguns grupos são valorizadas e instituídas como cânone, as de outros são desvalorizadas e proscritas" (p. 166). A cultura produz tudo e a todos e todas. Ela nos faz sentir vergonha, procurar outras identificaçôes, mas também nos faz sentir orgulho de pertencimento. A cultura é ambivalente. A cultura ${ }^{1}$ diz quem nós somos, o que não devemos ser, o que devemos nos tornar, como devemos nos comportar, que lugares sociais podemos ocupar. A cultura associa, muitas vezes, a diferença com inferioridade. A cultura produz a lugarização (Bauman, 2001), demarcando os lugares que cada um pode/deve ocupar. A cultura legitima a idéia de que alguns devem viver em favelas e outros em mansōes. A cultura produz a idéia de que alguns devem ser sem-terra e outros latifundiários. A cultura (branca, o mito da democracia racial) produz [equivocadamente] a idéia de que não ser branco é ser inferior, é ser menos, portanto não merece o mesmo salário, acesso à universidade (principalmente se ela for pública e federal!), não merece ter acesso igual aos bens materiais. ${ }^{2}$ A cultura posiciona os sujeitos, estabelece as fronteiras entre o "bem" e o "mal", produz os "deuses" e os "demônios". A cultura atravessa tudo. Isto significa dizer que todos os seres humanos são produtores de cultura e ao mesmo tempo um produto da cultura. Daí que não faz sentido falar em mais cultura, menos cultura, baixa cultura, alta cultura. Todos somos sujeitos de cultura e da cultura.

Mas a cultura não faz só isso. A cultura é ambivalente. É cheia de práticas contraditórias. A cultura faz com que as pessoas fiquem indignadas diante das injustiças, diante das discriminaçōes/racismos, diante da dor do outro e da outra. A cultura produz os movimentos negros de resistência. A cultura produz o Movimento dos Trabalhadores Sem Terra. Produz os movimentos feministas, os movimentos gays... A cultura produz a coragem e a convicção de lutarmos com as nossas for- 
Articulando raça e classe: efeitos para a construção da identidade afrodescendente

ças e estabelecermos alianças para minarmos os processos de dominação/exploração, discriminação e racismo. A cultura produz as identidades e as diferenças.

As identidades/diferenças culturais são o resultado de inúmeros e infinitos processos de negociação cultural (Bhabha, 2001) que se desenvolvem em contextos específicos e em condições particulares de emergência. Como decorrência disso, há a impossibilidade de fixar, essencializar e cristalizar tanto as identidades quanto as diferenças. Segundo Hall (2003), em nenhum outro momento histórico a vida cultural, sobretudo do Ocidente, foi tão perturbada e transformada pelas vozes das margens como agora. ${ }^{3}$ Mais do que uma abertura promovida dentro dos espaços dominantes, essa perturbação é o resultado das políticas culturais da diferença desenvolvidas pelos "diferentes": "Isto vale não somente para a raça, mas também para outras etnicidades marginalizadas, assim como o feminismo e as políticas sexuais no movimento de gays e lésbicas, como resultado de um novo tipo de política cultural" (Hall, 2003, p. 338).

$\mathrm{O}$ artigo insere-se neste contexto de políticas culturais, ${ }^{5}$ no qual posições cristalizadas são perturbadas pelas vozes e experiências de grupos que reivindicam a sua diferença como legítima. Sabemos que no Brasil a educação de qualidade, muito mais do que um direito, continua sendo um privilégio para poucos. À medida que aumenta o nível de ensino, diminuem as chances das classes populares terem acesso a ela. Quando estas classes populares são negras, por razões históricas de discriminação e preconceito, as dificuldades são maiores ainda.

Porém, apesar dessas dificuldades, os afrodescendentes, por meio de muita luta, organização e resistência, subvertem a lógica da exclusão do ensino superior e, ao ocuparem este espaço, afirmam sua identidade cultural/racial, contribuindo positivamente para que mais sujeitos deste grupo cultural e de outros grupos culturais em situação de desvantagem sintam-se encorajados para lutar e ocupar lugares tradicionalmente freqüentados pelos grupos dominantes.

A problemática deste texto centra-se em um desses movimentos, o Projeto Negraeva, nascido na comunidade São Benedito, comunidade negra, localizada no município de Campo Grande (MS). A entrada das classes populares, no caso estudantes afrodescendentes, na universidade representa um fator decisivo para o processo identitário para os 
sujeitos diretamente envolvidos, bem como para todo o grupo racial. Este aspecto positivo começa antes mesmo da entrada na universidade, pois, para que esta se torne possível, são necessários encontros, reuniões, discussões, ou seja, é preciso uma forte organização popular. Nestes grupos desenvolve-se um sentimento de pertencimento racial, por meio do qual seus membros vão se fortalecendo para enfrentar os processos discriminatórios aos quais são submetidos cotidianamente, seja pelo tipo de trabalho que exercem (empregada doméstica, faxineiro...), pelas piadas, pelas práticas pedagógicas, pela exploração maior (salários mais baixos)... Nesse sentido, cabe destacar, na íntegra, a explicação da coordenadora do Negraeva, universitária beneficiada pelo projeto:

Nunca, ninguém, nenhum de nós tinha experiência de montar projeto. Nunca escrevemos um projeto sequer e aquele era o primeiro projeto que a gente sentava para fazer. Depois disso, num final de semana a gente discutindo, o professor ${ }^{6}(. .$.$) chega na comunidade para fazer uma visita, vai na$ minha casa conversar com a minha mãe e ele vê o grupo reunido, num domingo à tarde sentado lá um grupo de jovens discutindo o que escrever, o que deixar de escrever e se interessou em saber o que a gente estava fazendo, pegou o documento foi ler, era o edital de convocação do Concurso. Entrou lá para dentro e continuou conversando, sentou e continuou conversando com a minha mãe e lendo o material e a gente lá escrevendo, discutindo, falando, o que a gente queria, o que a gente deixava de querer. Daí ele voltou e perguntou: mas o que vocês estão tentando fazer? Nós estamos tentando montar o projeto, (...) a entrada dos alunos, de nós negros na universidade. Ele disse: Eu vou ajudar vocês, eu posso ler o que vocês estão escrevendo. Ele disse: vocês começaram pelo lado contrário de um projeto. Aí ele sentou com a gente, explicou item por item do edital (...). Então é o seguinte, nós não queremos que a universidade venha, adote o projeto e venha executar dentro da comunidade, a proposta nossa é nós elaborarmos o projeto e nós executarmos. A universidade, ela pode nos auxiliar, mas ela jamais será a executora do projeto aqui dentro da comunidade, nós queremos ser os sujeitos da nossa história (...). Fechamos o projeto em cima disso, passamos o Natal, o Ano Novo, janeiro, todo sentado em cima do projeto. A gente ia para a casa do professor (...) nos finais de semana, oito horas da manhã, saía três e meia, quatro horas da manhã. Ele levava a gente em casa... na porta da casa, no outro dia voltava, durante a semana a gente ia para a casa dele, ia para a universidade, escrevia com ele, ainda a gente escrevia e mandava para ele dar uma olhada, ele mandava a gente voltar e fazer isso, buscar, pesquisar... Assim foi feito o projeto, depois de tudo nós passamos por uma, tipo uma banca do Movimento Negro. A gente apresentou ele no fórum das entidades do Movimento Negro e o único projeto que foi todo anotadinho, todo 
Articulando raça e classe: efeitos para a construção da identidade afrodescendente

estruturadinho para apresentar foi o nosso, as outras entidades deram desculpas de que o disquete não abria, outra deu a desculpa que tinha esquecido o trabalho em casa... e o único projeto apresentado foi o nosso, para o fórum. Só fomos nós a apresentar. (Âna)

Neste sentido, para compreender alguns efeitos para a construção da identidade cultural que o acesso à universidade por meio Projeto Negraeva propicia, é que foram entrevistados os universitários participantes do projeto Negraeva, criado em 2002 com o objetivo de apoiar financeiramente universitários negros da comunidade São Benedito. São ao todo 17 sujeitos, que concluíram seus cursos em 2005 ou estão em fase de conclusão. As entrevistas foram individuais, gravadas e posteriormente transcritas, realizadas no próprio ambiente universitário. Todos os sujeitos contatados se dispuseram a participar da pesquisa, entendendo que esta poderia ser uma forma de divulgar positivamente o projeto, bem como as políticas de cotas para universitários negros. Como afirma Ana, universitária do projeto:

Eu espero que essa pesquisa que está sendo feita com o Projeto Negraeva, com os alunos do Projeto, que ela mostre não só para os alunos, mas também que ela possa ser usada dentro da academia de uma forma, de uma ação afirmativa, positiva, realmente positiva... Você trabalhar a valorização do aluno negro, a permanência dele, a sua manutenção dentro da universidade é muito importante. Não basta só a bolsa, o financeiro, mas o apoio pessoal que cada aluno recebe dentro da universidade, dos seus professores é fundamental.

Utilizo esta fala para introduzir um dos elementos que considero central, tanto na discussão de uma ação afirmativa como do ponto de vista teórico, bem como uma das implicações para a construção da identidade cultural, isto é, se a discussão deve pautar-se em torno da classe a que estes sujeitos pertencem ou se é uma questão racial. Tal discussão justifica-se à medida que se observou pelas entrevistas realizadas que todos, sem exceção, apontaram como a maior dificuldade enfrentada no ensino superior a questão financeira, inclusive esta sendo destacada como o motivo pelo qual alguns universitários do projeto acabaram desistindo. Mesmo a aluna anteriormente citada, que afirmou não ser só uma questão financeira, destacou num outro momento da entrevista que a sua maior dificuldade foi financeira e, por este motivo, quase abandonou a universidade. 
Assim, num primeiro momento, parece que somos levados a acreditar que, de fato, a classe é mais decisiva do que a raça. Porém, ao efetuarmos uma análise, tendo como campo teórico os Estudos Culturais, desconstruímos esta primeira noção e começamos a entender que não se trata de uma discussão ao estilo ou/ou (ou classe/ou raça), mas de uma articulação que tem

(...) a grande vantagem de nos possibilitar pensar como práticas específicas (articuladas em torno de contradiçôes que não surgem da mesma forma, no momento e no mesmo ponto) podem todavia ser pensadas conjuntamente. (Hall, 2003, p. 152)

Articular a raça com a classe não tem sido uma tarefa fácil ${ }^{7}$ no campo dos Estudos Culturais. Hall (op. cit.), ao fazer a genealogia destes Estudos, lembra que

(...) fazer com que os estudos culturais colocassem na sua agenda as questôes críticas de raça, a política racial, a resistência ao racismo, questóes críticas da política cultural, consistiu numa ferrenha luta teórica. (Idem, ibid., p. 210)

A tendência geralmente acaba sendo ou um determinismo de classe ou um determinismo de raça, não vendo as inúmeras articulações produzidas na vida social. Ambos não dão conta de compreender os processos identitários. $\mathrm{O}$ determinismo de classe não permite compreender as inúmeras diferenciações "(...) tais como as divisões sociais e as contradições que surgem em torno de raça, etnia, nacionalidade e gênero" (idem, ibid., p. 304). Já o determinismo de raça deixa de olhar para o necessário atravessamento econômico que todas as dimensões da vida têm, inclusive a construção da identidade cultural. $\mathrm{O}$ acesso ou não a determinados bens materiais implica uma forma específica de identidade cultural e racial. A dimensão econômica atravessa a raça e a cultura e vice-versa. Segundo Hall (2003), raça é “(...) a categoria discursiva em torno da qual se organiza um sistema de poder socioeconômico, de exploração e exclusão - ou seja, o racismo" (p. 69, grifo nosso).

A não-aceitação do inter-relacionamento economia e raça "(...) provou ser um dos problemas teóricos mais difíceis e complexos de se abordar" (idem, ibid., p. 327). Parece que as opçōes disponíveis são a aceitação de que a raça é uma decorrência das forças de trabalho, portanto da economia, ou o contrário: negligencia-se a exploração do capital e 
Articulando raça e classe: efeitos para a construção da identidade afrodescendente

enfatiza-se a centralidade da raça. Diante dessas duas possibilidades, que, segundo Hall (2003), são abordagens reducionistas, o desafio é compreendê-las de forma articulada, isto é, reconhecer que elas podem ou não estar relacionadas, dependendo do contexto em que são produzidas, gerando efeitos diferentes, igualmente dependentes de seu contexto.

Portanto, raça e questões de classe não estão necessariamente relacionadas em todos os contextos, mas não faz sentido concluir que nunca estarão, quando se observa essa desvinculação em alguns momentos. Da mesma forma, não se pode inferir o contrário, ou seja, o fato de haver relação em alguns contextos levar à conclusão de que sempre haverá. Tudo depende dos processos específicos e das condições particulares de emergência. Quando observo que os alunos do projeto Negraeva apontam que o fator financeiro é o maior problema, não posso deixar de reconhecer a classe como categoria importante. Mas daí a concluir que tudo se explica pela classe seria um equívoco, pois seria não levar em conta o papel que a cultura opera sobre os sujeitos, por meio dos inúmeros discursos que circulam, instituindo posições de sujeito, legitimando modos de vida e de conduta, desautorizando outros. É pela cultura (branca) que os sujeitos negros foram sendo representados como inferiores, e em decorrência desta representação ainda hoje são mais explorados economicamente. Como afirma Valente (1994, p. 23): "Como justificativa da escravidão negroafricana, os países colonialistas alegaram que os negros pertenciam a uma raça inferior, possuíam costumes primitivos, e por isso era necessário que fossem 'civilizados' e 'cristianizados'. A exploração econômica só se reproduz por meio de um conjunto de "justificativas" construídas no interior da cultura. Munanga (1999, p. 51), analisando os pensadores do Brasil pós-escravista, afirma: "Toda a preocupação da elite, apoiada nas teorias racistas da época, diz respeito à influência negativa que poderia resultar da herança inferior do negro nesse processo de formação da identidade étnica brasileira”. Mesmo que o autor esteja se referindo ao período posterior à escravidão, pode-se argumentar que esse receio esteve presente desde a chegada dos portugueses. Observa-se, assim, que a exclusão dos negros do mercado de trabalho assalariado (questão econômica) tornou-se possível por causa dos significados culturais produzidos e impostos pela classe/raça branca.

Ao seguir a articulação entre raça e classe como forma de compreender os efeitos do acesso à universidade na construção da identidade cultural dos afrodescendentes, lembro que existe toda uma discus- 
são teórica que envolve o uso do termo "raça" e que não pode ser desconsiderada. Esse termo foi fortemente acentuado no século XIX, quando era entendido como um conjunto de características naturais e físicas portanto, biológicas - vistas como qualidades ou déficits de determinados grupos humanos. Ou seja, mesmo que a raça fosse vista como uma essência biológica que diferenciava os grupos, ela logo foi estendida para "(...) os domínios social e político e seus pressupostos regulavam, também, a vida nas colônias na época" (Meyer, 2000, p. 65). Diante dessa ênfase biológica do termo "raça" é que foi introduzido o conceito de etnia para enfatizar as questôes culturais e os processos de produção das identidades e diferenças. Porém, os Estudos Culturais enfatizam que a raça não é uma categoria biológica, mas discursiva: "Raça' é uma construção política e social" (Hall, 2003, p. 69). Além disso, não é a simples substituição do termo "raça" por "etnia" que resolve a questão, até porque na construção das identidades e diferenças, "Na maioria das vezes, os discursos da diferença biológica e cultural estão em jogo simultaneamente" (idem, ibid., p. 71). Nesse sentido, conforme Hall (2003) e considerando que, com a "crítica pós-estruturalista ao conceito de 'raça', que o vê como sendo ele próprio uma construção discursiva e cultural, as distinçōes entre os dois termos tendem a desaparecer" (Silva, 2000b, p. 56), utilizo raça/etnia, mas entendendo que tanto uma quanto a outra são construçōes culturais, atravessadas por relações de poder. Elas não são essenciais, naturais ou biológicas. Elas são relacionais, construídas social, política e culturalmente.

No dizer de Hall (2003), mesmo que a introdução de ambivalência, hibridismo e interdependência perturbe e transgrida "(...) a estabilidade do ordenamento hierárquico binário do campo cultural em alto/baixo, não destroem a força operacional do princípio hierárquico da cultura" (Hall, 2003, p. 239). Ainda: “(...) não mais se pode dizer, pelo fato de a 'raça' não ser uma categoria científica válida, que 'de forma alguma enfraquece sua eficácia simbólica e social”" (idem, ibid.).

Além do que já foi apontado, é necessário salientar que o fato de todos os entrevistados terem destacado o aspecto financeiro como o mais decisivo para a sua manutenção na universidade, e ao mesmo tempo a maior dificuldade enfrentada, tem a ver com o tipo de universidade que os sujeitos desta pesquisa freqüentam: trata-se de universidades particulares que, por sua própria lógica de organização, só permitem que seus alunos façam a rematrícula se estiverem rigorosa- 
Articulando raça e classe: efeitos para a construção da identidade afrodescendente

mente em dia com o pagamento das mensalidades. Assim, pelos depoimentos dos entrevistados pode-se depreender que, de fato, era uma angústia permanente causada pelo atraso no pagamento, pelas tentativas frustradas de renegociação das dívidas, pelas bolsas sociais da própria Instituição que tinham que ser conquistadas, uma vez que os recursos conseguidos pelo Projeto Negraeva eram insuficientes para cobrir as mensalidades (um salário mínimo, enquanto a mensalidade variava de 1,7 a 2,5 salários mínimos, dependendo do curso) e só existiram durante um ano:

No meu caso é condições financeiras. Você tem que trabalhar o dia inteiro. Aí vir para a universidade à noite, sem janta, muitas vezes sem dinheiro para comprar um lanche, sem dinheiro para tirar xérox. (Ana)

Eu trabalhava como doméstica, ganhava um salário mínimo. Então quando eu entrei aqui eu ganhava duzentos e vinte reais que era o salário mínimo e a mensalidade era trezentos e setenta. (Sara)

Dificuldades financeiras, porque a Fundação ${ }^{8}$ foi só um ano que deu esta ajuda financeira. Depois acabou essa ajuda que a gente tinha. Então para mim foi complicado por isso. Porque o salário meu não era condizente com o valor da mensalidade, mas acabei. Minha dificuldade maior foi a financeira. (Lúcia)

Antes de fazer este curso, eu já tinha passado por aqui três vezes. Comecei três cursos e parei. Falta de recursos. (Lia)

Reitero que esta constatação econômica, longe de poder ser explicada de forma desvinculada da questão racial, está na verdade profundamente articulada com esta, como já argumentei anteriormente. Raça e classe principalmente no Brasil possuem uma estreita vinculação, como continuam mostrando os números do IBGE (Brasil, 2003): 21\% das mulheres negras são empregadas domésticas e dessas somente $23 \%$ têm carteira assinada, ao passo que $12,5 \%$ das mulheres brancas trabalham como empregadas domésticas, sendo que $30 \%$ delas têm carteira assinada. Considerando todas as profissões, $22,4 \%$ dos negros trabalham sem carteira assinada ao passo que em brancos esse número cai para 16,2\%. Além disso 5,9\% dos brancos são empregadores e apenas $2,3 \%$ de negros são empregadores. Também na saúde as mulheres negras estão em desvantagem: $46,27 \%$ delas nunca fizeram exame de prevenção contra o câncer de mama, ao passo que esse número diminui para $28,73 \%$ para mulheres brancas. $\mathrm{Na}$ educação ocorre o mesmo: 
ainda que na última década (1993-2003) se observe um aumento da média de estudo dos brasileiros em torno de 1,5 anos, não houve diminuição significativa entre o tempo de estudo dos brancos e negros (caiu de $2,1$ para 1,9$)$. $O$ analfabetismo continua muito maior entre os negros $(16,8 \%)$, ao passo que entre brancos é de $7,1 \%$. Com todos estes indicativos, não é surpresa que os dados apontem que quanto à distribuição de renda observa-se que dos $10 \%$ mais pobres no Brasil, $64,6 \%$ são negros e apenas $22,3 \%$ de negros fazem parte dos $10 \%$ mais ricos. Além disso, $43 \%$ dos negros encontram-se abaixo da linha de pobreza enquanto esse índice é de $20 \%$ entre os brancos.

Como se pode perceber pelos números do IBGE, os negros estão em desvantagem em todos os segmentos pesquisados: saúde, emprego, renda, educação. Tudo isto mostra, como estamos argumentando, que a questão racial está articulada com a questão de classe e por isso pensamos que elas devem ser pesquisadas desta forma. $\mathrm{O}$ outro dado que não deixa dúvidas quanto a esta imbricação de classe e raça é o que revelou o Índice de Desenvolvimentos Humano (IDH) de 2005: o Brasil ocupa o $72^{\circ}$ lugar. Porém, se o IDH fosse calculado somente entre a população brasileira branca ocuparia o $44^{\circ}$ lugar e, do outro extremo, se fosse considerado apenas o IDH de brasileiros negros estaria no $105^{\circ}$ no ranking mundial. Desta forma pode-se afirmar que vivemos um apartheid racial camuflado, encoberto, aquilo que muitos autores vêm denominando de mito da democracia racial (Munanga, 1999; Santos, 1997; Candau, 2002; Gonçalves, 2000; Rosemberg, 1996; Gomes, 2003, e outros).

Apesar da ênfase dada ao aspecto econômico, cujas razões já explicamos, assim como seu atravessamento racial, observa-se também pelas entrevistas realizadas com os sujeitos, que sua presença na universidade, ainda que indiretamente, contribuiu para o seu processo de afirmação enquanto identidade racial/étnica. Afirmo indiretamente porque muitos davam mais ênfase ao projeto e a sua comunidade do que ao acesso à universidade. Considerando que o projeto existiu em função do acesso à universidade, percebe-se que há uma contribuição, ainda que de forma não direta. Neste sentido destaco:

Meu curso não fala especificamente desta questão. Mas o projeto me ajudou, o projeto Negraeva me ajudou a ter conhecimento. Porque antes de entrar no projeto eu não tinha interesse em procurar e dentro do projeto não. A gente tinha reunião com o grupo de acadêmicos, a gente discutia sobre a 
Articulando raça e classe: efeitos para a construção da identidade afrodescendente

questão racial, então era bom... Tinha um esclarecimento, trabalho de autoestima com a gente. Isso foi muito bom. (Lúcia)

Algumas vezes esta importância para a construção da identidade cultural pode ser percebida por meio da prática de uma professora da universidade, militante do Movimento Negro:

Para mim ela foi um exemplo de luta, porque aquela mulher é muito determinada. Ela sabe o que quer (...). Eu muitas vezes não concordava com algumas coisas que ela falava porque quando você é adolescente você quer é curtir a vida. Só que hoje eu vejo que é certo... (Lia)

Outras vezes, questionando atitudes de professores que não percebiam suas atitudes/falas discriminatórias:

Às vezes eles faziam algumas colocaçôes que eram pejorativas. Eu não deixava escapar. Eu cobrava. "Pô professor não é assim!" Questionava a posição dele e muitas vezes o professor se sentia intimidado pela maneira como eu me colocava na frente da sala, pela colocação que ele fazia sobre alguma reportagem ou por alguma expressão que ele usava que é muito comum. "Ah, porque neguinho se acha" (...). Por que ninguém fala assim? "Porque branquinho se acha!”. Ninguém fala porque branquinho não é pejorativo, mas o neguinho é. (Ana)

Ainda, os efeitos na identidade cultural podem ser percebidos por meio do questionamento de colegas (brancos) de aula, que ao "branquearem" os negros pensavam que estavam fazendo um elogio, não percebendo a discriminação implícita que os motivava. Como explicita Sara:

A gente começava a discutir a questão do negro. Eu comecei a falar que sou negra. Sempre tinha aquelas pessoas que diziam: não você não é negra, você é morena. Negra é a fulana. Eu tinha que impor. Eu sou negra! Eu não vejo nenhum problema em ser negra. As pessoas é que criam obstáculos para as pessoas negras (...). Hoje em dia eles me respeitam e me vêem como negra.

Também o fato de estarem fazendo um curso superior é um elemento importante para a construção da identidade cultural, como se pode observar na fala da aluna Rosimeire: "Entrar na universidade fortalece muito a gente. A gente tem que mudar isso: que negra nasceu para ser empregada doméstica, para o trabalho braçal. A gente tem que lutar para conquistar o nosso espaço”. De modo semelhante, Lúcia des- 
taca: "Ajuda porque você tem um estudo. Você tem um conhecimento, você vai estar a par dos seus direitos (...). Você já é discriminado. Então se você não for preparada, vai ser pior ainda...”. Sem contar que a presença de alunos negros acaba servindo de motivação para que outros também se sintam capazes: "Eu estou fazendo curso superior. Estou concluindo o meu curso. Sou uma das poucas negras que está fazendo. Então eu estou sendo uma força para mostrar para outras pessoas do meu bairro que isso é possível" (Lia).

Como vimos, vários são os efeitos que o acesso à universidade tem para os sujeitos que historicamente foram excluídos deste espaço. Os Estudos Culturais sustentam que as identidades são construídas na relação com os outros em contextos culturais e sociais: "A identidade e a diferença têm que ser ativamente produzidas (...). Somos nós que as fabricamos, no contexto de relações culturais e sociais. A identidade e a diferença são criações sociais e culturais" (Silva, 2000a, p. 76). Assim, quando os sujeitos freqüentam o ambiente universitário, quando este ambiente passa a fazer parte do seu universo social e cultural, estes passam a ter mais força para reivindicar direitos, questionar atitudes discriminatórias, desconstruir o mito da democracia racial, construindo uma identidade cultural/racial/étnica de forma a se verem e serem vistos pelos outros como uma identidade legítima, que não pode ser usada para justificar a dominação e a exploração econômica, como se fez e se faz no Brasil desde os tempos da colonização.

Recebido em maio de 2006 e aprovado em junho de 2006.

\section{Notas}

1. Entenda-se, os sujeitos da cultura.

2. Como os dados do IBGE (2003) continuam evidenciando.

3. Observem-se os grandes embates suscitados pelas políticas que visam estabelecer cotas para negros, índios e estudantes da escola pública em universidades públicas federais.

4. Destaco a luta incansável dos movimentos negros que estão forçando a adoção de políticas públicas da diferença.

5. Políticas culturais entendidas como as lutas de poder em torno dos significados válidos, das identidades "legítimas", dos processos de significação e ressignificação inerentes a toda cultura.

6. A coordenadora cita o nome do professor.

7. Moreira (2001), ao analisar a produção científica sobre currículo e multiculturalismo no Brasil chama a atenção para a "secundarização da categoria classe social" (p. 72), entenden- 
Articulando raça e classe: efeitos para a construção da identidade afrodescendente

do que se trata de uma inquietação e motivo de preocupação, ainda mais por sermos um dos países mais desiguais do mundo.

8. A aluna está se referindo à Fundação Ford, que financiou o Projeto Negraeva e de fato esta ajuda financeira (um salário mínimo) foi só para o primeiro ano do curso, para todos os 17 integrantes.

Referências bibliográficas

BAUMAN, Z. Modernidade líquida. Rio de Janeiro: Zahar, 2001.

BHABHA, H. O local da cultura. Belo Horizonte: Editora da UFMG, 2001.

BRASIL. Instituto Brasileiro de Geografia e Estatística. Pesquisa Nacional de Amostragem por Domicílio (PNAD). Rio de Janeiro: IBGE, 2003.

CANDAU, V.M.F. Sociedade, cotidiano escolar e cultura(s): uma aproximação. Educação \& Sociedade, Campinas, ano 23, n. 79, p. 125-162, ago. 2002.

DONALD, J. Liberdade bem regulada. In: SiLva, T.T. (Org.). Pedagogia dos monstros: os prazeres e os perigos da confusão das fronteiras. Belo Horizonte: Autêntica, 2000. p. 61-88.

HALL, S. A centralidade da cultura: notas sobre as revoluções culturais do nosso tempo. Educação \& Realidade, Porto Alegre, v. 22, n. 2, p. 15-46, jul./dez. 1997.

HALL, S. Da diáspora: identidades e mediações culturais. Belo Horizonte: Editora da UFMG, 2003.

GOMES, N.L. Uma dupla inseparável: cabelo e cor da pele. In: BARbosa, L.M.A.; Gonçalves E Silva, P.B.; Silvério, V.R. (Org.). De preto a afrodescendente: trajetos de pesquisa sobre relações étnico-raciais no Brasil. São Carlos: UFSCAR, 2003. p. 137-150.

GONÇALVES, L.A.O. Negros e educação no Brasil. In: Lopes, E.M.T.; Faria Filho, L.; Veiga, C.G. (Org.). 500 anos de educação no Brasil. Belo Horizonte: Autêntica, 2000. p. 325-346.

MEYER, D.E.E. Identidades traduzidas: cultura e docência teuto-brasileira-evangélica no Rio Grande do Sul. Santa Cruz do Sul: EDUNiSC; São Leopoldo: Sinodal, 2000. 
MOREIRA, A.F.B. A recente produção científica sobre currículo e multiculturalismo no Brasil (1995-2000): avanços, desafios e tensões. Revista Brasileira de Educação, São Paulo, n. 18, p. 65-81, set./out./ nov./dez. 2001.

MUNANGA, K. Rediscutindo a mestiçagem no Brasil: identidade nacional versus identidade negra. Petrópolis: Vozes, 1999.

ONU. Relatório de Desenvolvimento Humano. Brasília: Programa das Nações Unidas para o Desenvolvimento (PNUD), 2005.

ROSEMBERG, F. Educação infantil, classe, raça e gênero. Cadernos de Pesquisa, São Paulo, n. 6, p. 58-65, fev. 1996.

SANTOS, L.H.S. "Um preto mais clarinho..." ou dos discursos que se dobram nos corpos produzindo o que somos. Educação \& Realidade, Porto Alegre, v. 22, n. 2, p. 81-115, jul./dez. 1997.

SILVA, T.T. Identidades terminais: as transformações na política da pedagogia e na pedagogia da política. Petrópolis: Vozes, 1996.

SILVA, T.T. A produção social da identidade e da diferença. In: SiLVA, T.T. (Org.). Identidade e diferença: a perspectiva dos Estudos Culturais. Petrópolis: Vozes, 2000a. p. 73-102.

SILVA, T.T. Teoria cultural e educação: um vocabulário crítico. Belo Horizonte: Autêntica, 2000b.

VALENTE, A.L. Ser negro no Brasil hoje. São Paulo: Moderna, 1994. 